\title{
A questão étnico-racial do cinema de Hollywood no ensino de história: uma experiência de estágio na educação de jovens e adultos
}

\author{
Diogo Matheus de Souza* \\ Stela Schenato**
}

\begin{abstract}
Resumo
Este artigo resulta da experiência de Estágio Supervisionado de História na Educação de Jovens e Adultos (EJA) de Florianópolis, em 2015. Objetivamos problematizar a utilização de filmes como documentos históricos no ensino da EJA, bem como socializar uma oficina por nós desenvolvida numa das etapas do estágio, cuja temática trata sobre como a questão étnico-racial é abordada pelos filmes de Hollywood "Histórias Cruzadas" (2011), "12 Anos de Escravidão" (2013), "O Mordomo da Casa Branca" (2013) e "Selma" (2014). Com base nessa experiência, aprendemos sobre a necessidade de se respeitar a diversidade existente no interior de uma sala de aula e de inovar com a utilização de diferentes fontes, conteúdos e perspectivas, desenvolvendo um processo de ensino de História que leve a compreender as discriminações e injustiças sociais.
\end{abstract}

Palavras-chave: estágio supervisionado de história, educação de jovens e adultos, cinema hollywoodiano.

The ethnic-racial question of Hollywood cinema in history teaching: an internship experience in youth and adult education

\begin{abstract}
This article results from the Supervised Internshipexperience in History Teaching of Youth and Adult Education (Educação de Jovens e Adultos - EJA) in Florianópolis during 2015. We aim to problematize the use of films as historical documents in the Youth and Adult Education, as well as socialize a developed workshop during one of the stage steps, whose theme is about how the ethnic-racial question is approached by Hollywood films"The Help" (2011), "12 Years a Slave" (2013), "The Butler" (2013) e "Selma" (2014).Based on this experience, we learned aboutthe respect need of classroom diversity,and also the need to innovate with the use of different sources, contents and perspectives, thusdeveloping a teaching History process that leads to understanding discrimination and social injustice.
\end{abstract}

Keywords: supervised internship in history teaching, youth and adult education, hollywood cinema.

Introdução

A utilização de filmes como documentos históricos e como recursos didáticos é um assunto recorrente na academia nos últimos anos, especialmente no campo do ensino de História. Dada a sua importância, não podemos entender a história da sociedade humana a partir do século XX sem conhecer o cinema por ela produzido

\footnotetext{
* Graduado em História na Universidade Federal de Santa Catarina. E-mail: souzamatheusdiogo@gmail.com.

** Graduada em História na Universidade Federal de Santa Catarina. E-mail: steschenato@ gmail.com.
} 
(MEIRELLES, 2004). Rosenstone (2010, p.106), um dos principais pesquisadores na área de cinema e história, afirma que "hoje em dia, a principal fonte de conhecimento histórico para a maioria da população é o meio audiovisual". Tal afirmação reforça ainda mais a necessidade de se utilizar este recurso como um meio favorável ao professor de História, em sala de aula. Quando analisado, criticado e discutido, o cinema pode proporcionar uma interessante oportunidade de aprendizado histórico e de formação de opinião. Pensando nisso, decidimos fazer uso da temática "história e cinema" em nossa experiência de Estágio Curricular Supervisionado, uma das etapas da formação inicial de professores, no curso de licenciatura em História, na Universidade Federal de Santa Catarina (UFSC).

O estágio possibilitou o contato com uma forma de ensino diferenciada, uma vez que foi realizado na Educação de Jovens e Adultos (EJA), no núcleo EJA Norte I, na Escola Básica Herondina Medeiros Zeferino, localizada no Bairro Ingleses, município de Florianópolis (SC). A experiência no estágio incluiu observações permanentes do cotidiano da EJA, diálogos com os estudantes e professores e também a elaboração de um projeto de ensino em forma de oficina temática, desenvolvida em uma das turmas. Essas atividades foram realizadas ao longo do ano de 2015 e serviram como ponto de partida para a reflexão desenvolvida neste artigo.

Um dos eixos norteadores da EJA de Florianópolis é o da Pesquisa como Princípio Educativo (PPE), buscando proporcionar o desenvolvimento da capacidade crítica dos estudantes por meio da atividade de formulação de perguntas/problematização e posterior pesquisa sobre assuntos do interesse deles próprios e/ou de outras necessidades. De acordo com as temáticas mais escolhidas pelos estudantes para suas pesquisas, os professores da EJA elaboram oficinas semanais (FLORIANÓPOLIS, 2008).

Considerando a relação das oficinas com as pesquisas, procuramos, ao longo do período de observação participante, identificar possíveis formas alternativas para os estudantes realizarem seus trabalhos e que fossem diferentes das que eles já costumavam utilizar. Conversando com eles, percebemos que, embora gostassem muito de filmes, raramente buscavam utilizá-los como fonte para obtenção de conhecimento e de exercício crítico. Daí surgiu a ideia de apresentar trechos de filmes e analisá-los com uma das turmas. 
A questão norteadora em torno da qual organizamos e desenvolvemos a oficina constituiu-se em problematizar como os alunos como a questão étnico-racial é tratada no cinema hollywoodiano, a forma como negros e negras são representados e qual o seu espaço no mundo cinematográfico. ${ }^{1}$ Além de comentarmos a presença de pessoas afrodescendentes na produção de filmes ao longo da história do cinema em Hollywood, desde o início do século XX até os dias atuais, fizemos uma seleção de trechos de filmes que foram lançados recentemente e que tiveram repercussão entre a crítica especializada, para serem problematizados na oficina e discutidos com os estudantes. Os filmes por nós selecionados e utilizados foram: "Histórias Cruzadas" (2011), "12 Anos de Escravidão" (2013), “O Mordomo da Casa Branca” (2013) e "Selma” (2014).

Tendo em vista o alcance e a importância que a indústria cinematográfica tem adquirido nos últimos anos, seja por meio do próprio cinema e televisão, ou por meio de novas mídias e tecnologias, como a internet, entre outros, é necessário que se discuta e se problematize sobre os usos e apropriações de professores e estudantes, evidenciando os limites e possibilidades de compreensão de um contexto histórico por meio da linguagem cinematográfica.

As pesquisas acadêmicas sobre cinema e história passaram a ser realizadas, sobretudo, a partir das décadas de 1970 e 1980. A discussão pioneira não poderia deixar de ser sobre a relevância dos filmes como fonte histórica. Os pesquisadores vêm desenvolvendo argumentos em relação a utilizar o cinema como instrumento reflexivo de trabalho e não como mero mecanismo de entretenimento ou apoio (RANZI, 1998). A historiografia no século XX já alertava para que a História utilizasse novas fontes de pesquisa. A nova história tem um peso significativo nesse aspecto, pois fez expandir muito o campo de possibilidades para o historiador, permitindo criar espaços para novas

Ao longo da história de Hollywood é perceptível que acontecem diversas mudanças na forma como os seus filmes são produzidos. Aqui trataremos da visão atual do cinema Hollywoodiano, fruto de uma tendência que já vem desde os anos 1970, no qual se tem um abandono do "cinema de arte americano" para dar lugar a uma indústria cinematográfica fortemente integrada (Mascarello, 2012). 
fontes e novos personagens. ${ }^{2}$ As pesquisas históricas foram se transformando ao longo do século XX e XXI, como exemplifica Ranzi (1999, p. 26): "a noção de texto e documento vem se ampliando na História e hoje todos os vestígios do passado são considerados matéria para o historiador. Essa tendência passou a incluir no elenco de fontes dignas de fazer parte da história, novos textos, tais como a pintura, o cinema e a fotografia".

Os historiadores e historiadoras da atualidade trabalham com um conceito amplo sobre o que vem a ser fonte histórica. Já se sabe que as fontes utilizadas não precisam ser tão somente escritas; toda fonte, independentemente de sua natureza, é passível de ser criticada e historicizada (XAVIER, 2010). Aliás, esse é um dos principais trabalhos do professor e pesquisador. Portanto, um filme, dentro de sala de aula, dependendo da forma como for trabalhado, pode trazer tantos questionamentos quanto um documento escrito.

Nesse alinhamento, dividimos este artigo em três partes. Na primeira parte realizamos uma breve análise bibliográfica sobre cinema, história e ensino, buscamos avaliar o que tem se produzindo pela academia, citando as principais referências e discutindo ideias dos autores em questão. Na segunda parte abordamos a EJA e a importância de se trabalhar com o cinema e a História nesta modalidade de ensino, pois trata-se de uma forma diferenciada de abordagem. Na terceira e última parte, apresentamos uma reflexão com base em filmes para ser desenvolvida em sala de aula. Essas sugestões são formuladas por intermédio da nossa oficina sobre cinema e a questão étnico-racial, conforme já mencionado.

\section{Produção bibliográfica sobre cinema e ensino de História}

Ao realizarmos um levantamento bibliográfico sobre o tema desenvolvido, percebemos que, entre os autores, há em geral um consenso sobre a importância de se trabalhar com filmes nas aulas de História, mas alguns destacam que, muitas vezes, o

\footnotetext{
A expressão Nova História é melhor conhecida na França e corresponde a uma corrente historiográfica surgida na década de 1970. La nouvelle histoire é o título de uma coleção de ensaios editada pelo renomado medievalista francês Jacques Le Goff. Trata-se de uma história made in France, e, mais exatamente, é a história associada à chamada École dês Annales, agrupada em torno da Revista Annales: économies, societés, civilisations. É escrita como uma reação deliberada contra o "paradigma" tradicional, ou visão do senso comum da história (Burke, 1992).
} 
uso dessa ferramenta acaba sendo utilizada de forma genérica pelos professores, sem que haja uma problematização maior dos objetivos de se utilizar um filme.

O uso de filmes como recurso didático não pode mais ser considerado como uma novidade educacional no Brasil. Diversos intelectuais ligados à corrente educacional da Escola Nova, na década de 1930, a exemplo de Fernando Azevedo, Afrânio Peixoto, Anísio Teixeira e Edgard Roquete-Pinto, dentre outros, já apontavam para o potencial do cinema na educação de crianças e jovens da época. ${ }^{3}$ Importante destacar esse período, marcado pela fermentação de um forte nacionalismo em construção no país, época em que a educação se tornou um dos alvos principais da gestão do Governo de Getúlio Vargas, o qual enxergava o cinema como uma forma de divulgar a cultura e contribuir na unificação do Estado nacional.

O que podemos perceber em relação ao uso dos filmes, especificamente no ensino de História, é que as décadas de 1970 e 1980 acabam sendo um "divisor de águas". Se com o movimento da Escola Nova os filmes passam a ser entendidos como ferramenta no ensino, a Nova História passará a entender os filmes também como um documento histórico. Esse é um momento, como já destacado, em que a historiografia amplia seus horizontes e apresenta novos métodos e objetivos de análise. Destaca-se, também, um alargamento dos meios de comunicação de massa no Brasil, fazendo com o que o cinema ganhe definitivamente espaço nas discussões pedagógicas, em livros e revistas científicas (NASCIMENTO, 2008).

Em relação à produção bibliográfica mais significativa sobre o cinema e o ensino nas últimas décadas do século XX, destaca-se a obra "Lições com Cinema" (1993), uma coletânea de textos de vários autores, publicada pela Fundação para o Desenvolvimento da Educação, da Secretaria de Educação do Estado de São Paulo, discutindo o uso do cinema no universo escolar de maneira interdisciplinar, com o objetivo de dar suporte ao trabalho do professor. Também podem ser citados trabalhos específicos na área da História, como a obra "Cinema e História do Brasil", de JeanClaude Bernadet e Alcides Freire Ramos, publicada pela Contexto de São Paulo, em 1994.

Escola Nova é um dos nomes dado ao movimento de renovação do ensino que foi especialmente forte na Europa, na América e no Brasil, na primeira metade do século XX. Disponível em: <http://www.educacional.com.br/glossariopedagogico/verbete.asp?idPubWiki=9577> Acesso em: 29 mai. 2016. 
Embora as obras citadas e outras sejam importantes, a maioria dos textos que utilizamos neste artigo tem Marc Ferro como principal teórico. Ferro é referência na discussão sobre cinema como fonte histórica para a pesquisa e também para o ensino. No trabalho intitulado "Cinema e História" (1992), o autor discute como o historiador deve estudar as fontes cinematográficas que, segundo ele, são tão legítimas quanto as fontes escritas, embora a forma de análise seja diferente. Ferro destaca os cuidados que o historiador precisa ter ao trabalhar com o cinema, porque os filmes retratam muito mais sobre o presente do que sobre o passado.

Pensando no ensino de História, nosso objetivo é apontar justamente para a necessidade de se refletir sobre o filme, sem utilizá-lo como "ilustração histórica", de modo a levar os estudantes a pensar que seja uma "verdade" histórica, mas sim como objeto de análise, com intenção de mensagem por parte dos envolvidos na sua produção, tais como, roteiristas, diretores, entre outros profissionais. Nesse sentido, concordamos com a visão de Marc Ferro ao indicar que o filme traz muito mais elementos sobre o presente do que sobre o passado. Por exemplo, se um filme atual tem como plano de fundo a escravidão no século XIX, pode ser porque exista a necessidade de se discutir a permanência de trabalhos análogos à escravidão em determinados lugares ainda no tempo presente. Um filme sobre a vida da primeira transexual da história, como "A Garota Dinamarquesa" (2015), pode dizer muito sobre a luta pelos direitos que transexuais têm desencadeado nos últimos anos.

Souza (2012, p. 73) cita que em estudos exploratórios realizados com estudantes de 13 a 16 anos de idade, em uma investigação sobre como entendiam a funcionalidade de um filme histórico, predominou a visão de que as produções cinematográficas têm a função de "mostrar o passado, ensinar ou informar sobre a realidade de um fato histórico, ou seja, ensinar a história de uma forma alternativa”. Percebemos que esses estudos mostram como os estudantes conseguem visualizar a relevância do cinema para o aprendizado de História, mas é um tanto preocupante acharem que um filme apresenta "a realidade de um fato histórico" (SOUZA, 2012, p. 74). Ademais, o autor destaca que a produção cinematográfica se configura como artefato cultural complexo, envolve diversos processos constitutivos, que abrangem escolhas e possibilidades técnicas, financeiras, culturais e políticas. Há, como já dito, uma intencionalidade de quem produz o filme de acordo com o público-alvo que se pretende atingir. 
Autores que estudam o uso do cinema em sala de aula, como por exemplo Souza e Soares (2013), analisam uma sala de aula do $6^{\circ}$ ano do ensino fundamental e identificam quais problemas aparecem ao se trabalhar com essa fonte no ensino. A conclusão é que, geralmente, os estudantes não se identificam com os temas históricos, pois não os relacionam com a sua vida cotidiana. Uma proposta de solução para esse impasse é feita por Caparrós-Lera e Rosa (2013). Essas autoras trazem propostas de filmes e como trabalhá-los, sugerindo que os professores não utilizem o filme tão somente como mera ilustração, mas que façam dessa ferramenta uma forma dos estudantes questionarem a própria realidade. Temas como questões étnico-raciais, gênero, economia, política, entre vários outros latentes na sociedade moderna, podem ser questionados e apresentados para estudantes conforme sua realidade social, por intermédio de filmes.

Numerosos outros trabalhos vêm sendo produzidos sobre a temática do cinema nos últimos anos, porém, algumas lacunas ainda podem ser observadas. Ao realizarmos o estágio na EJA e procurarmos referências para a elaboração da oficina, percebemos que não existe uma bibliografia específica que trata sobre o uso do cinema nessa modalidade particular de ensino. A próxima seção tem justamente o objetivo de adentrar neste caminho, com o intuito de trazer a nossa contribuição para os trabalhos referentes ao cinema e o ensino de História.

\section{A EJA de Florianópolis e o perfil dos estudantes}

A estruturação da Educação de Jovens e Adultos (EJA), em Florianópolis, teve início em meados da década de 1990. Anteriormente ao modelo de ensino via PPE e divisão de segmentos (alfabetização $1^{\circ}$ a $4^{\circ}$ anos e $5^{\circ}$ a $8^{\circ}$ anos), a EJA oferecia somente um programa de alfabetização do $1^{\circ}$ ao $4^{\circ}$ anos.

Em 1995, o Conselho Municipal de Educação de Florianópolis, atendendo a demanda, autoriza o funcionamento do Ensino Supletivo de $5^{\circ}$ a $8^{\circ}$ anos. Em 2000 a EJA sofre uma mudança em sua estruturação com a criação da Divisão de Educação Continuada, responsável, a partir de então, pelo seu funcionamento. Cada Núcleo da EJA passa a ter um professor articulador e os professores das determinadas áreas de conhecimento. 
O modelo pedagógico de "ensino pela pesquisa" tem como objetivo fazer com que o aluno seja agente e produtor de conhecimento, realizando pesquisas sobre temáticas do seu interesse, com a orientação de um dos professores da EJA. Como muitos dos alunos que frequentam a EJA tem histórico de fracasso escolar no ensino regular, o novo modelo procurava incluir esses alunos colocando-os como centro do processo de ensino.

A demanda por um sistema de alfabetização em Florianópolis começou na década de 1980. Com o crescimento e visibilidade, a cidade atraiu migrantes de várias partes do país, que vinham com a intenção de se estabelecer e conseguir emprego. A maioria dessas pessoas teve que abandonar os estudos para poder trabalhar, ajudar a família ou até porque não se encaixavam no modelo de educação regular. Diferentes motivos, como a paternidade ou maternidade precoce, separação dos pais, problemas psicológicos, entre outros, levaram esses alunos a abandonar a escola (SOUTO, 2009).

O perfil dos estudantes da EJA, hoje, não é muito diferente. Muitos dos alunos mais jovens não se adaptaram no sistema regular de ensino ou tiveram que ajudar os pais na manutenção da casa. As pessoas de mais idade costumam ter o mesmo histórico, porém, se afastaram por mais tempo do ensino. Conversando com os alunos percebemos que grande parte deles não é da cidade de Florianópolis, veio do interior de Santa Catarina ou de outro Estado para tentar a vida, sozinhos ou com familiares. Dessa forma, entram na EJA para poder se inserir no mercado de trabalho ou pela vontade de concluir o ensino fundamental e dar continuidade aos estudos no Ensino Médio. A idade predominante é de 15 a 20 anos, poucos são os alunos que têm mais de trinta anos (DÁRIO DE CAMPO, 2015).

Esses alunos que trabalham e são muito novos, em torno de 15 e 17 anos de idade, dificilmente teriam possibilidade de frequentar o ensino regular, portanto, enxergam a EJA como uma possibilidade de dar continuidade a sua formação escolar. Os estudantes têm perfis muito diferentes. $\mathrm{O}$ ensino pela pesquisa proporciona que o aluno desenvolva seu próprio conhecimento levando em conta seus limites e também potencialidades.

Na metodologia da EJA, a utilização de fontes diversificadas é muito bem vinda, já que tanto alunos quanto professores têm maior liberdade em relação ao conteúdo a ser trabalhado. Porém, como observamos na experiência de estágio, fontes diversificadas 
são pouco exploradas, tanto em sala de aula - em relação às pesquisas - quanto nas oficinas, ofertadas pelos professores. Nossa atenção, rapidamente, se direcionou em levar para a EJA essas novas possibilidades de se trabalhar História em sala de aula. Conversando com os alunos percebemos que um dos elementos de divergência era em relação à experiência cinematográfica. Alguns gostavam muito de assistir filmes, já outros falaram que raramente tinham tempo para se dedicar a esse tipo de lazer, embora gostassem muito de assistir.

Ao longo da nossa oficina sobre o cinema e a questão étnico-racial, ficou claro que enquanto determinados alunos conheciam muito sobre filmes e eram bastante participativos, outros diziam conhecer nada ou pouco sobre o assunto, ou, em alguns casos, nem se manifestavam. A discussão acabou tendo então importância no aspecto da coletividade e da troca de experiências entre estudantes. O fato de um estudante compartilhar o que conhece a respeito de filmes pode servir como um incentivo para aqueles que não costumam ter contato com essa fonte.

Assim, o trabalho com filmes torna-se especialmente útil no sentido de que pode provocar a admiração e o interesse dos alunos pelas mais diversas temáticas e indagações sobre a sociedade, mobilizando referências e contribuindo para a construção de novas argumentações históricas (SCHMIDT; CAINELLI, 2010). Ao apresentarmos trechos do filme "O Mordomo da Casa Branca", tratando da segregação racial dos Estados Unidos nas décadas de 1950 e 1960, alguns alunos imediatamente passaram a fazer questionamentos sobre a permanência de problemas como este na sociedade atual, problematizando se ainda existem locais públicos onde há algum tipo de preconceito racial e segregação. Percebemos como o cinema acaba sendo também uma ótima fonte histórica para se fazer relações entre passado e presente.

A pluralidade dos estudantes da EJA é uma questão importante para se considerar ao trabalhar com o uso de filmes como fonte de pesquisa. Conseguimos perceber que entre os estudantes existem indivíduos com as mais diversas experiências de vida. Há casos de pessoas de mais idade que resolvem voltar a estudar por prazer, de adolescentes que se tornaram pais ou mães precocemente, daqueles que, assumidamente, já passaram por algum tipo de problema psicológico, como o caso de mulheres que sofreram violência doméstica, e também daqueles que precisam passar o dia trabalhando e ainda vão para o Núcleo no horário noturno. Investigar essas 
40 Polyphonía, v. 29/1, jan./jun. 2018

experiências e utilizar filmes que possam problematizá-las e serem objetos de investigação é um recurso interessante tanto para o professor quanto para o aluno.

Portanto, pensamos que a combinação do formato de ensino da EJA de Florianópolis e as novas propostas do ensino de História se complementam e precisam andar juntas para um maior aproveitamento do ensino. A questão não é somente utilizar o cinema como fonte histórica, mas utilizar as produções humanas que representem a diversidade da qual a sociedade é composta: música, teatro, pintura, quadrinhos, jornais, revistas, grafite, vestígios arqueológicos, entre tantas outras fontes que produzimos ao longo da história.

Uma experiência e proposta: conhecer os filmes antes de utilizar em sala de aula

Como descrevemos anteriormente, nossa intenção foi fazer um trabalho diversificando as fontes históricas utilizadas em sala de aula. Nós tínhamos espaço para trabalhar uma oficina com os alunos, com conteúdo selecionado por nós. Seguindo essa lógica resolvemos trabalhar com a indústria cinematográfica, em específico a de Hollywood. Escolhemos essa indústria cinematográfica por ter maior proximidade com os alunos, já que a maioria tem acesso a filmes que são transmitidos em canais da televisão aberta.

Escolhemos trabalhar com a seguinte questão: como os negros e negras são representados no cinema de Hollywood e como são inseridos e representados na indústria cinematográfica ao longo da história? Na EJA, nossa preocupação foi em relação a um tema que fosse fazer os alunos questionarem seu próprio cotidiano. $\mathrm{O}$ perfil étnico do Núcleo que trabalhamos, a maioria é de negros. Logo, pensamos que o tema ligar-se-ia muito bem com a realidade daqueles estudantes, problematizando algumas imagens e preconceitos em relação às questões étnico-raciais.

Iniciamos a oficina contextualizando sobre a história do cinema e do racismo, principalmente nos Estados Unidos da América, lugar que concentra uma das mais importantes indústrias cinematográficas do mundo - Hollywood. Apresentando esse breve histórico, mostramos elementos sobre um país no qual os alunos têm muito contato por meio da mídia, mas que costumam saber pouco sobre sua história e práticas efetivas. $\mathrm{O}$ interessante de mostrar a história do racismo, partindo da escravidão até a 
segregação racial nos Estados Unidos, é que, assim, os alunos ficam melhor situados para poderem contextualizar os filmes por nós escolhidos.

Como elaborar uma análise fílmica com os alunos? Primeiramente, como se trata de uma fonte visual que exprime opinião e uma ideia formada, necessita de uma reflexão em relação a sua produção. Um dos elementos interessantes que podem ser analisados, falando de uma fonte visual, como os filmes, é seu ano de produção. Assim o aluno pode identificar elementos/opiniões da época em que foi produzido. Outro elemento é a autoria, neste caso, quem é o diretor e o roteirista do filme. Cada diretor e roteirista cinematográficos têm uma forma de trabalho, fazem opções em relação à filmagem, enredo e temática. Nessa análise, procuramos verificar se o diretor era negro ou branco, mulher ou homem e quais os tipos de trabalho que vem produzindo. Pensamos que esses elementos influenciam quando estivermos analisando a inserção e representação de negros e negras no cinema.

Os filmes escolhidos, conforme já listados anteriormente, para tratar sobre a questão étnico-racial foram "Histórias Cruzadas" (Tate Taylor, 2011), "12 Anos de Escravidão" (Steve McQueen, 2013), "Selma” (Ava DuVernay, 2014) e "O Mordomo da Casa Branca" (Lee Daniels, 2014). O filme "12 Anos de Escravidão" trata da história de um homem negro americano que é sequestrado e colocado na condição de escravo durante doze anos, longe de sua família; e os outros três versam sobre o período dos movimentos pelos direitos civis dos negros nos Estados Unidos, entre as décadas de 1950 e 1970.

O filme "Histórias Cruzadas" envolve a relação de empregadas domésticas negras com as suas patroas brancas na década de 1960 nos Estados Unidos. Selecionamos trechos que evidenciam o preconceito racial nessa relação, no qual uma empregada negra, por exemplo, não pode utilizar o banheiro da patroa por medidas de higiene. Os trechos selecionados de "12 Anos de Escravidão" dialogaram com "Histórias Cruzadas", uma vez que apresentam a violência física e psicológica que a escravidão envolvia, e pudemos refletir com a turma como essa violência, de certa forma, permaneceu mesmo depois do fim da escravidão.

Buscamos a todo o momento deixar claro que um filme não, necessariamente, retrata a realidade, ele deve ser sempre criticado, pois, tem um objetivo na sua produção. No caso de "Histórias Cruzadas", levantamos a hipótese de que o filme pode 
reforçar uma concepção de que os negros são dependentes de brancos no reconhecimento de seus direitos, já que na história existe uma jornalista branca que pretende escrever um livro dando voz às empregadas negras e suas trajetórias de vida.

O filme "O Mordomo da Casa Branca" trata sobre a história de Eugene Allen, filho de escravos que se tornou mordomo da Casa Branca. A cena que escolhemos para analisar representa a luta dos negros contra a discriminação e, ao mesmo tempo, a subjugação pela qual viviam. A intencionalidade em mostrar a cena era fazer um paralelo com os dias atuais, porém, o debate girou em torno dos direitos dos negros ao longo da história até os dias de hoje. A turma chegou à conclusão de que mesmo que não tenhamos leis de segregação racial no momento atual, negros e negras ainda se privam de certos lugares porque neles não são bem-vindos. A questão se entrelaça com um vídeo que passamos ao final da aula do rapper Emicida, ${ }^{4}$ em que discursa sobre a desigualdade racial no Brasil e o racismo latente que ele e todos os negros enfrentam diariamente.

"Selma" (2014) foi um dos filmes que focamos bastante na oficina, uma vez que é dirigido por Ava DuVernay, mulher e negra, característica rara entre os diretores hollywoodianos. O filme conta a história da marcha por direitos eleitorais que aconteceu em Selma - Alabama. A cena escolhida envolve a primeira tentativa de marcha feita pelos manifestantes em Selma, mostrando a violência sofrida por eles. O seguimento da aula se constituiu de um sentimento de indignação por parte da turma, pois o filme aborda a intencionalidade da marcha como sendo pacífica, porém, o xerife Jim Clark e o governador George Wallace não pareciam muito interessados em que ela continuasse. Para que os alunos entendessem melhor o movimento de resistência negra nos EUA, iniciamos a explicação sobre os direitos civis da década de 1960, contexto que foi retratado no filme Selma. Duas personalidades tratadas foram Martin Luther King Jr. e Rosa Parks, exemplificando também o início do movimento de resistência.

Para finalizar essa explanação tratamos do Partido Panteras Negras, que teve forte influência nos EUA até a década de 1990. A turma teve participação ativa ao longo do debate. Um aluno trouxe uma interessante relação entre o super-herói Pantera Negra da Marvel e o Partido Panteras Negras. Alguns dos estudantes também conheciam vários outros filmes que tratavam da temática e se interessaram em comentá-los na em: 07 jun. 2015. 
oficina. Houve uma identificação da turma com o tema, e também um envolvimento no momento da apresentação dos trechos dos filmes. Procuramos sempre levantar elementos que as cenas traziam, demonstrando que um filme não deve servir apenas de ilustração do conteúdo, mas deve sim ser problematizado.

A análise fílmica, do conteúdo e representação das cenas, é um momento em que nós nos tornamos mediadores e ajudamos os alunos a fazerem suas interpretações. $\mathrm{O}$ professor tem a função de fazer perguntas que incitem o debate em sala de aula, por exemplo: O que é realçado nessas cenas? Qual época o filme está retratando? Quais as suas intenções? O filme procura atingir um grupo de pessoas em particular? O filme representa a realidade? (SCHMIDT; CAINELLI, 2010). Esses são somente alguns exemplos de questionamentos para que o debate se inicie. No caso da EJA, em que a pluralidade das turmas costuma ser grande, é natural encontrar casos de identificação com as determinadas pautas encontradas nos filmes.

A análise fílmica necessita ter introdução, desenvolvimento e conclusão. Como se estivéssemos desenvolvendo uma pesquisa. A introdução dessa proposta foi contextualizar o documento que estávamos utilizando, trazendo informações sobre sua datação, autor e críticas sobre os filmes. Foi importante apresentar o objetivo da aula e como seria utilizado o documento em questão. Começamos o desenvolvimento da oficina contextualizando a temática e depois partindo para a crítica e análise fílmica. Buscamos questionar, com o auxílio da turma, a presença dos negros e negras nas premiações do Oscar e nos filmes comerciais. Os questionamentos giraram em torno de: quantos negros e negras ganharam a premiação do Oscar desde sua criação em 1926 ? Em que tipos de filmes e papéis esses atores ou atrizes ganharam reconhecimento do seu trabalho com o Oscar? Com que frequência vemos negros e negras serem protagonistas de filmes? Nos filmes comerciais, com que frequência vemos negros e negras no elenco? Esses questionamentos levaram os alunos a questionarem o mundo cinematográfico e as representações dos filmes que foram apresentados em sala.

Finalmente abrimos o debate para que os alunos inserissem esses questionamentos no contexto em que vivem no seu dia a dia. Essa prática pode fazer o aluno se questionar sobre os preconceitos existentes na sociedade, ser mais crítico em relação às mídias que tem contato e perceber que podemos construir o conhecimento histórico criticamente. 


\section{Considerações Finais}

O cinema é hoje um dos elementos culturais mais populares e significativos que existe, seja no Brasil, como em outros lugares do mundo. Todo filme produzido possui um objetivo e um público-alvo a ser atingido, podendo servir tanto como uma forma de propor debates como um meio de doutrinação, dependendo dos usos.

O estágio curricular supervisionado de História na EJA serviu para termos contato com um método de ensino diferenciado, ambiente em que a pluralidade social e cultural é uma característica latente das turmas, assim como no ensino regular, e onde o cinema pode tanto servir de fonte para as pesquisas dos estudantes quanto ser um meio para visualizarem e questionarem a sua realidade.

$\mathrm{Na}$ oficina desenvolvida na EJA, conseguimos trabalhar com vários filmes sobre a questão étnico-racial e pudemos observar um interesse e identificação da turma. Obviamente, alguns aspectos podem ser melhorados em experiências futuras. Foi necessário selecionar apenas alguns trechos dos filmes, em vez de apresentá-los na íntegra. A escolha de tratar sobre quatro filmes em uma única noite foi um risco que corremos. Embora tenha dado certo, consideramos que o ideal seria diminuir este número quando o tempo de trabalho é assim reduzido. Ainda foi necessário escolher entre seguir o script do planejamento para a oficina, ou dar atenção para o que os alunos estavam achando interessante.

Finalmente, com essa experiência também aprendemos e esperamos ter, neste artigo, deixado claro que o respeito à diversidade é um elemento indispensável em sala de aula. Entrar em contato com a EJA de Florianópolis nos fez perceber que uma nova perspectiva de educação - ensinar pela pesquisa - é possível, mesmo com dificuldades no ensino público. Em nossa experiência procuramos utilizar conceitos diversificados de história, fontes, problemáticas e atividades, auxiliando o estudante a perceber que ele é um agente da história.

\section{Referências}

AREND, Silvia Maria Fávero. Trajetórias das famílias dos/as estudantes da EJA (FLORIANÓPOLIS, 1980-2007). In: SILVA, Cristiani Bereta; TORQUIST, Carmen 
Suzana (Org.). Histórias e trajetórias de jovens e adultos em busca da escolarização. Florianópolis: UDESC, 2009, p.71-79.

BURKE, Peter. A Nova História, seu passado e seu futuro. In: BURKE, Peter (Org.). A escrita da História: novas perspectivas. São Paulo: UNESP, 1992, p. 1-13.

FLORIANÓPOLIS. Estrutura, Funcionamento, Fundamentação e Prática na Educação de Jovens e Adultos (EJA) - 2008. Florianópolis: Departamento de Educação Continuada. 2008, 60p. Disponível em: http://www.pmf.sc.gov.br/arquivos/arquivos/pdf/22_02_2010_9.36.57.04162e08d6cd8876612adc5ada3 75bd5.pdf/>. Acesso no dia: $1^{\circ}$ jun.2016.

MASCARELlO, Fernando. História do Cinema Mundial. Campinas: Papirus, 2012. 432p.

MEIRELLES, William Reis. O Cinema na História. O uso do filme como recurso didático no ensino de história. História \& Ensino, Londrina, v. 10, 2004, p. 77-88.

MOCELLIN, Renato. História e cinema: Educação para as mídias. Curitiba: Editora do Brasil, 2008. 88p.

NASSARALA, Nair Leite Ribeiro. Ensino de História e o Cinema: reflexões para a prática. Mimesis, Bauru, v. 31, n. 1, 2010, p. 53-64.

NASCIMENTO, Jairo Carvalho do. Cinema e Ensino de História: Realidade Escolar, Propostas e Práticas na Sala de Aula. Fênix - Revista de História e Estudos Culturais, Ilhéus, v. 5, n.2, 2008, p.01-23.

RANZI, Serlei Maria Fischer. Cinema e aprendizagem em história. História ensino, Londrina, v.4, 1998, p.25-33.

ROSENSTONE, Robert A. A história nos filmes, os filmes na história. Tradução: Marcello Lino. São Paulo: Paz e Terra, 2010, 262p.

SCHMIDT, Maria Auxiliadora; CAINELLI, Marlene (Org.). Ensinar História: Pensamento e ação na sala de aula. São Paulo: Scipione, 2009, 160p.

SOUTO, Regina Bittencourt. A EJA na cidade de Florianópolis. In: SILVA, Cristiani B. TORQUIST; Carmen Suzana (Org.). Histórias e trajetórias de jovens e adultos em busca da escolarização. Florianópolis: UDESC, 2009, p.28-47.

SOUZA, Éder Cristiano de. O uso do cinema no ensino de história: propostas recorrentes, dimensões teóricas e perspectivas da educação histórica. Escritas, Araguaína, v.4, 2012, p.70-93.

SOUZA, Polyana Jessica do Carmo; SOARES, Valter Guimarães. Cinema e ensino de história. ANPUH. Natal, 2013, p.1-7.

XAVIER, Erica da Silva. Ensino e História: o uso das fontes históricas como ferramentas na produção do conhecimento histórico. XXII Semana de História da Universidade Estadual do Norte do Paraná. Jacarezinho: UENP, 2010, p. 639-654. 
46 Polyphonía, v. 29/1, jan./jun. 2018

Filmes

A GAROTA Dinamarquesa. Direção: Tom Hooper. Produção: Eric Fellner. [s.1.]: Working Title Film, 2015. 119 min. DVD, Son (legendado). Cor.

HISTÓRIAS Cruzadas. Direção: Tate Taylor. Produção: Chris Columbus. [s.1.]: Walt Disney Studios Motion Pictures, 2011. 137 min. DVD, Son (legendado). Cor.

SELMA: Uma luta pela igualdade. Direção: Ava DuVernay. Produção: Oprah Winfrey. [s.1.]: Paramount Pictures, 2014. 128 min. DVD, Son (legendado). Cor.

O MORDOMO da Casa Branca. Direção: Lee Daniels. Produção: Lee Daniels. [s.l.]: The Weinstein Company, 2013. 132 min. DVD, Son (legendado). Cor.

12 ANOS de escravidão. Direção: Steve McQueen. Produção: Brad Pitt. [s.l.]: Fox Pictures, 2013. 134 min. DVD, Son (legendado). Cor.

Recebido em: 27 abr. 2018.

Aceito em: 28 maio 2018. 